Copyright (C) 2015 by Academic Publishing House Researcher

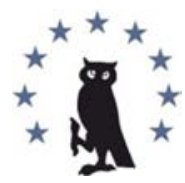

Published in the Russian Federation

European Researcher

Has been issued since 2010.

ISSN 2219-8229

E-ISSN 2224-0136

Vol. 94, Is. 5, pp. 365-372, 2015

DOI: 10.13187/ er.2015.94.365

www.erjournal.ru

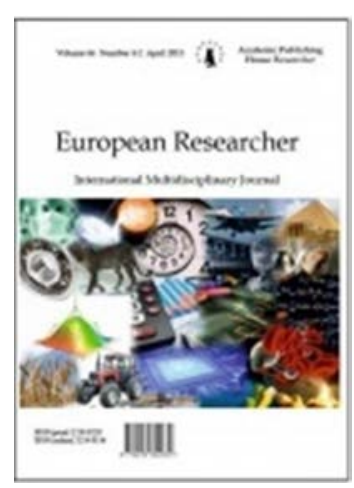

UDC 33

\title{
Service Quality and Patients' satisfaction in Tunisian Public Hospitals
}

\author{
Ghrab Hatem
}

Graduate School of Business of Tunis, Tunis

$\mathrm{PhD}$

E-mail: ghrabhatem@yahoo.fr

\begin{abstract}
The aim of this paper is to identify perceived quality of Tunisian public hospitals and its effect on patients' satisfaction. Our empirical analysis focused on three public hospitals (Charles Nicole, Rabta, Habib Thamer). By means of a questionnaire administered to a sample of 300 patients, we could shed light on the satisfaction process of patients in hospitals, check whether there is a relationship between perceived quality and satisfaction and finally we could establish the presence of a relationship between patients' satisfaction and perceived quality.
\end{abstract}

Keywords: public service, perceived quality, satisfaction.

\section{Introduction}

It is commonly admitted that either for a public service or private one, success of the firm comes from the quality of the relationship between service provider and the customer. To gain a better image, satisfy the customer and respond to their needs, the firm should evaluate the perception of the quality of its services. This is true for all sectors and in particular for the health sector, where patients look for being taken in charge and treated well. Then, it is a sector that requires a good service quality more than any other sector. Specifically, public hospitals are unique as they are submitted to regulation and frequent intervention of the State, which may affect the image and quality of services offered despite constraints of the system.

At first we think that evaluating patients' perceived image is for this purpose a good indicator that gives an idea about the hospital and the level of satisfaction of its patients.

It is in this global context that our work is referenced and in this article we will try to study the perceived quality of public hospitals and its effect on patients' satisfaction. To carry out this work we should answer a set of questions:

-What are the different criteria used to assess perceived quality of public hospitals?

-What is the degree of importance of these criteria?

-What are the different service elements that contribute to patients' satisfaction?

- Did perceived quality affect patients' satisfaction?

\section{Review of the Literature:}

Definition and foundations of the concept of perceived quality

Many definitions of quality have been developed in the literature. Eigler and Langlard (1987) define it as "a good quality service and which, in a given situation, satisfies the customer". 
For Zeithmal et al (1981) perceived quality represents the consumer's judgment about the degree of excellence or superiority assigned to an entity. For Grönroos (1984) "perceived quality of a service is the result of a comparison between customer expectations and actual experiences of a service". Parasurman et al (1985) also stress that it results from a mismatch between expectations and perceptions of consumers.

The results of some marketing studies of hospitals on the concepts of service quality and satisfaction, mainly American, cannot be ignored while studying in depth the concepts of perceived quality and satisfaction.

There are several major studies that focused on the study of quality assessment in the health sector such as that of Ware et al. (1983). They, in fact, developed a questionnaire to measure patient satisfaction. They offer eight dimensions: human relations, technical quality of care, accessibility and facilities, Economics, efficiency of care, continuity of care, physical environment, and Availability.

Doctorate in hospital marketing Bielen (2001) and the Hospitals of the National Federation of Medical and Social Associations of Belgium have developed a questionnaire on the evaluation of hospital stay which was given to any patient hospitalized. The aim is to measure patients' perceptions of the performance of the considered service attributes. The methodology that was used is based on the SERVPERF model (Cronin and Taylor, 1992; 1994). Changes were made to the dimensionality of perceived quality of service in order to provide a solution tailored to the specific health care in general and hospital care in particular. Seven components were identified instead of the original five. These seven components are broken down into 40 items. The components identified by Bielen, 2001) are: tangibility, attention, availability, insurance, communication, reliability, and Externality.

Solomon, Gasquet, Mesbah and Ravaud (1999) developed a reliable and valid instrument measuring patients' opinions on the quality of hospital care. Their instrument has eight dimensions: medical information, medical practice, attention and availability of nurses, respect for patients, psychological and social support, daily routine and team support, continuity and coordination and exit management.

Several other authors have studied the issue of quality and satisfaction in the area of health services. We can mention Allen and Rogers (1996) who conducted a study to measure the performance of health plans by user survey and compared it with the promised objectives. Meanwhile Rubin and Materko (1990) proposed to measure satisfaction based on different time steps of a hospital stay: the admissions office, emergency room, hospitality, nursing, medical and other exit and financial aspects.

The study of Hall et al. (1993) state that satisfaction correlates with the previous and current health status, i.e., the sickest patients tend to be less satisfied with the care than healthier patients.

These authors have shown that satisfaction and overall evaluation of medical care are strongly related to the perceived health status of the subject. Rubin (1990), citing Spelman, Ley and J ones, showed that patient assessments are related to psychological problems. As for the results of Bruster et al. (1994), the main issues are essentially communication, pain and exit management of.

Similarly there is also the study conducted in Canada in 1996 by Prevost and Fafard (1996). The authors identified four dimensions of service in all satisfaction assessment polls i.e. relational, organizational size, dimension and professional aspects of services related to the living conditions of the people interviewed. In this study, 35 items were identified.

\section{Theoretical analysis of satisfaction measurement}

Singh (1990) defines patient satisfaction "as the result of a process of evaluation and comparison of a service obtained from stakeholders and elements of the physical environment during hospital service delivery".

In the area of health services, in particular hospital services, we signal out the affective and cognitive dimensions of satisfaction, with some authors putting focus on the important role played by emotions in the development of satisfaction. Dube, Belanger et al (1996), Brown and Kirmani (1999), Brown and Kirmani (1999), highlighted the importance of anxiety in the patient's perception of a service experience.

Several searches, mostly Anglo-Saxon, proposed dimensions used by the patient to assess their experience of hospitalization. Some like Ware and Snyder (1975) provide critical dimensions 
of the overall experience of hospitalization. Other authors such as Brand, Cronin et al (1997), Kolb, Race et al (2000) propose dimensions specific to the situation of hospitalization or some types of patients (age, gender, hospital services ...).

According to Rumpler (2004) "literature in the area of patient satisfaction in hospitals is based around four dimensions:

- Interpersonal relationships with different categories of staff (medical and paramedical, nursing, administrative).

- The technical quality of care which refers mainly to the skills and professional practices.

- The physical environment (hospital and providing "hotel services" - catering).

- The different procedures of reception, consultation coordination, exit".

The problem with this measure is that satisfaction as a psychological step cannot be easily and directly observed.

Anderson (1997) distinguishes three criteria to be taken into account when measuring.

- Objective of the study: is it about maximizing satisfaction or minimizing dissatisfaction

- Objective or subjective nature of the measure.

- The time of measurement: two stages can be distinguished:

- Initial stage: immediately after the purchase or consumption.

- Final stage: after a while allowing reception of any complaints from consumers to process and respond to.

According to Pascoe (1983), "patient satisfaction is defined as the reaction to their personal experience during the service". This quote is interpreted by some authors such as, Pourin. C, Barberger Gateau P, Michel. P and R Salamon (1999), as implying that satisfaction is a cognitive development (concept of knowledge) and emotional response (affective domain) to structures, procedures and outcomes of the service.

Several models are used the models made by Staines (1995) to measure the satisfaction. One of these models is the disconfirmation model. It shows that "consumers satisfaction (S) is equal to the perception $(\mathrm{P})$ of the presentation provided to them and the one they had previously: $\mathrm{S}=\mathrm{PA}$ ". This model assumes that satisfaction comes from an overlap between consumer expectations and perception. Expectations are the expectations that customers have of the likely performance of the product or service. They then assess the performance of this brand or service during its consumption. When performance is better than expected, customers are satisfied, otherwise they are dissatisfied, and moderately satisfied when performance is in line with expectations.

\section{Research Methodology}

Our empirical approach is based specifically on a study based on data collected from a survey of patients in some public hospitals in Greater Tunis. Hospitals in which we conducted our investigation are three in number; RABTA hospital CHARLE NICOLE hospital and HABIB THAMER hospital.

In our study, we chose non-probabilistic sampling by which a selection of a population element is based in a large part on the researcher's criterion.

Of the non-probabilistic sampling methods, we chose reasoned convenience sampling. It is a rational choice as we tried to interview only those patients who are not in much pain in order for them to respond to our survey. We selected also patients in the following services: cardiology, diabetic, orthopaedic and surgical services.

Similarly, distribution took place in the concerned hospitals in the patients' rooms themselves, outside of visiting hours.

We interviewed 100 patients at each hospital. We wanted to examine more than 100 per hospital, but giving the time constraints, or the inherent difficulties of the health sector we retained a total of 300 patients.

\section{Data Analysis}

To check for the dimensionality and reliability of our measures, i.e., the different dimensions of quality and satisfaction in the Tunisian context, we conducted two PCAs with varimax rotations using the Statistical Package for the Social Sciences software (SPSS), version 12.0. The first PCA is for perceived quality and the second is for satisfaction. 


\section{Satisfaction Map:}

For each dimension of quality of the three hospitals (Charles Nicole Habib Thamer and Rabta) we calculated the average satisfaction as well as average importance done through changing the scale from (0 to 10$)$ to ( -5 to 5 ). For each hospital, we thus obtained a satisfaction map. This map will be very useful to guide marketing decisions on service data.



Figure 1: Charles Niole satisfaction map

Figure 2 : Rabta satisfaction map

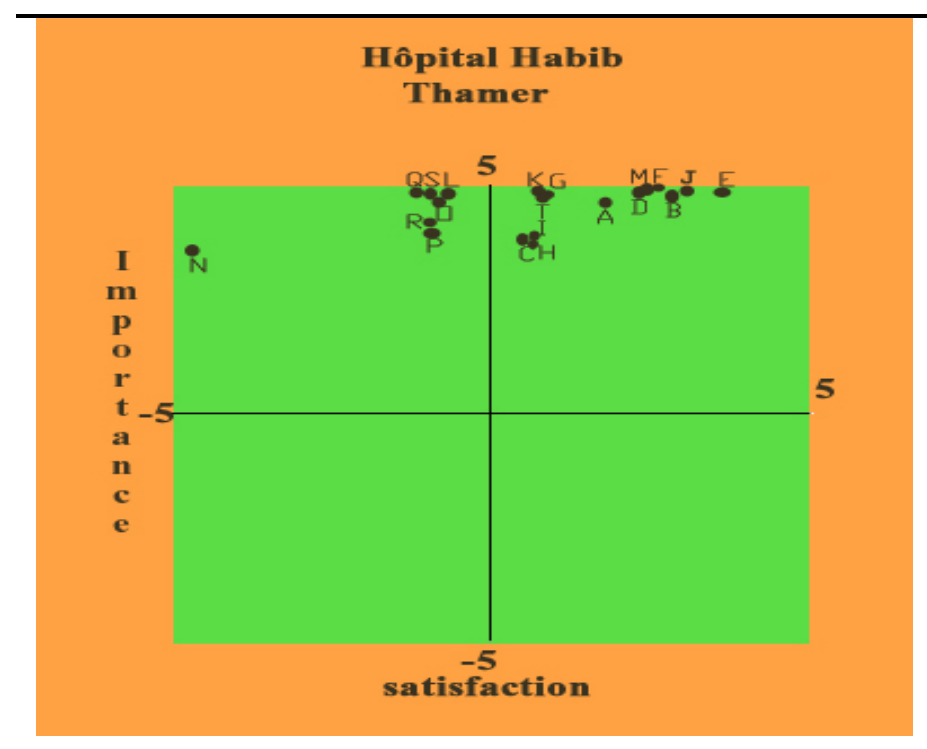

Figure 3 : Habib Thamer satisfaction map

$\begin{array}{ll}\text { A: reception of the } & \mathrm{J} \text { : provided day } \\ \text { administrative staff } & \text { care } \\ \text { B: reception of } & \text { K: provided night } \\ \text { health care staff } & \text { care } \\ \text { C: Information on } & \text { L: provided } \\ \text { your rights and } & \text { weekend care } \\ \text { duties } & \text { M: offered room } \\ \text { D: Explanation of } & \text { services } \\ \text { your health case } & \text { N: The comfort of } \\ \text { E: respect for your } & \text { your room } \\ \text { privacy } & \text { O: Meal times } \\ \text { F: physician } & \text { P: The presentation } \\ \text { availability } & \text { of the meal } \\ \text { G: nurses } & \text { Q: The quality of } \\ \text { availability } & \text { meals } \\ \text { H: Politeness of } & \text { A: The amount of } \\ \text { staff } & \text { food } \\ \text { I: friendliness of } & \text { S: The temperature } \\ \text { staff } & \text { of the meal } \\ & \text { T: Noise }\end{array}$

Analysing the satisfaction map (figures 1, 2, 3) allowed us to notice that "provided weekend care", "comfort of the room", "meals times", "the quality of the meal", "the amount of the meal", and "the presentation of the meal" are important expectations but underperforming. The map suggests that paying attention to these aspects to take their place at the top right of the map. 


\section{The relationship between perceived quality and satisfaction}

Our analysis allowed us to determine that there is a strong correlation between the first component and the following variables: physician availability, nurses availability, staff politeness, staff friendliness, day care quality, night care quality which allowed us to label this component: Care Quality.

The second component strongly correlates with the variables quality of meal times, quality of meal presentation, quality of meals, quantity of meals, and temperature of the meal. This component is labelled Food Quality.

The variables quality of the information on the rights and duties of visitors, quality of explanations about the health status of the patient, respect of patient privacy are highly correlated with the third component which may be labelled Communication Quality and Relevance of Information.

Finally, the fourth component is labelled Hospital Accommodation Quality following its strong correlation with the variables quality of services offered in the room and the comfort of the room.

We also noted that each satisfaction variable correlates with at least one other variable which explains the use of a PCA. For example, there is a strong correlation of 0.812 between the variable patient satisfaction and physician availability and patient satisfaction and nurses availability. There is also a strong correlation of 0.864 between this variable and politeness of the staff. Similarly, we note that the use of PCA is relevant: Bartlett's significance is equal to 0.000 and KMO index is about $82.7 \%$.

The analysis allowed us to identify a strong correlation between the variables patient satisfaction with meal times, meal presentation, quality of meals, quantity of meals, temperature of meals and the first component, hence the label: satisfaction with provided food component. The second component has a strong correlation with the variables patient satisfaction with physician availability, nurses availability, politeness of staff, friendliness of the staff, provided night care, provided day care, provided weekend care, then this component can be identified as the satisfaction with care services component.

The third component can be labelled: the satisfaction with communication and relevance of information component because of its strong correlation with the variables patient satisfaction with the information on the rights and duties of visitors, explanation of health status. The fourth component can be labelled satisfaction with hospital accommodation because of its high correlation with the variables patient satisfaction with provided room services and comfort of the room. Finally, there is a strong correlation between the variable patient satisfaction and respect for patient privacy and the fifth component then we may retain the name of this latter variable.

In our analysis, the age variable has a significant relationship with the components: quality of food, quality of communication and relevance of information and quality of hospital accommodation. But the regression of this variable with the component of care service quality is not significant as a whole. This is justified by the significance of the 0.124 value. This finding makes sense because care service quality can not be a dependent linear function of age however food, communication and hospital accommodation can be largely affected by the age of the individual.

In our empirical study, we found that the gender variable has no effect on the care service quality or food quality components or quality of communication and relevance of information component, or hospital accommodation quality. This is justified by the significance of values that are greater than 0.05 and which are respectively $0.087,0.587,0.123$, and 0.333 . This result makes sense because gender has no effect on the quality offered by Tunisian hospitals.

The results indicate that the CSP variable has no effect on food quality, the quality of communication and relevance of information and hospital accommodation quality. However, this variable has a significant relationship with care quality component.

According to the results, the variable profession affects care quality, quality of communication and relevance of information and hospital accommodation quality, yet this variable has no effect on food quality component. This finding can be seen as logical as in the Tunisian context profession largely affects Tunisians' assessment of the accommodation offered, the care and communication provided. 
We note also that accommodation affects only quality of communication and relevance of information component.

In our study, we notice that the variable length of stay has a significant relationship with the care quality and food quality and there is no significance between this variable and the other two components: the quality of communication and relevance of information, and quality of hospital accommodation.

In our analysis, the simple regression of care service quality on length of stay and quality of food provided on this variable are significant and this can be justified by the significance of the regression coefficients which are respectively 0.016 and $\beta=\beta=-0.0244$. We also note that these two statistics are not very strong as $\mathrm{R}^{2}$ for the first order regression is 0.026 , i.e $2.6 \%$ of the variance of care service quality is explained by the variable length of stay and the remaining $97.4 \%$ is explained by other variables not taken into account.

For the second regression, $\mathrm{R}^{2}$ is equal to 0.059 , i.e. $5.9 \%$ of the variance of the quality of food provided is explained by the variable length of stay. However, the variable length of stay can not explain in a meaningful way quality of communication and relevance of information and hospital accommodation quality.

\section{Multiple regression of satisfaction on perceived quality components:}

We find that the regression model is significant as a whole and $62 \%$ of the variance of satisfaction with provided food quality component is explained by the four components of perceived quality, more specifically by the second component namely food quality. This is justified by the fact that only the latter component has a significant regression coefficient $\beta=0.785$, with a confidence interval of $[0.714,0.855]$. However, satisfaction with care service component is explained largely by the first component namely care service quality where the regression coefficient is about 0.921, which is statistically significant. However, food quality and housing quality have a significant low effect on satisfaction with care service component by Tunisian patients. This explains the adjustment coefficient $\mathrm{R}^{2}$ which is quite high and significantly equal to 0.866 where only $13.4 \%$ of the variance of satisfaction with care service depends on other variables other than the four components of perceived quality.

Similarly, we note the importance of quality of communication and relevance of information for patients' satisfaction. Meanwhile, satisfaction with hospital accommodation by the Tunisian patient depends on hospital accommodation quality and food quality with a low intensity. The regression coefficient for the first component is 0.274 (statistically significant coefficient) and for the second component, the coefficient is 0.222 , in contrast other components of perceived quality have insignificant coefficients. This result largely explains the low value of $\mathrm{R}^{2}$ which is equal to $12.6 \%$.

Finally, the analysis also indicates that privacy of the Tunisian patient does not depend on the four components of perceived quality; rather it depends on other variables which are not the subject of this study. This is explained primarily by the fact that no component of perceived quality has a significant regression coefficient, and secondly by a low value of the linear adjustment coefficient $\mathrm{R}^{2}$, which is about $1.5 \%$ and explains $98.5 \%$ of the variance of the respect for privacy component. This latter component is explained by other variables other than care service quality, provided food quality, quality of communication and relevance of the information and hospital housing quality.

\section{Conclusion}

In our paper, we tried to' examine the relationship between perceived quality and patient satisfaction, ie, what are the different criteria used to assess perceived quality in public hospitals? What is the level of these criteria? What are the different elements that contribute to patient satisfaction? does perceived quality have an effect on patient satisfaction?

To check the theoretical assumptions, we studied the case of Tunisian public services, namely health services. We chose three public hospitals, where we surveyed 300 patients. Through this empirical study, we came to confirm the presence of a positive relationship between perceived quality and satisfaction of patients and to test the hypotheses we mentioned in the general introduction section which are: first, the positive effect of perceived quality on patients satisfaction; 
secondly the impact of some individual variables on the variable quality and the variable satisfaction, and finally the impact of the variable length of stay on the latter two.

The specific conclusion we have drawn from this Tunisian case study is the importance of variable privacy as a central component of the Tunisian patient's satisfaction. This can be explained by the socio-cultural context and especially the effect of the patient's ethics.

These results enable for a better guidance of applied marketing strategies in hospitals, i.e considering the above-mentioned aspects to improve the quality of services offered in Tunisian hospitals and even for a better knowledge of the characteristics of Tunisian patients to better meet their specific needs.

However, our study suffers some limitations:

The first methodological limitation is that we have worked with a convenience sample thereby reducing the external validity of our research. At this level, our investigation is part of an exploratory process that should be completed by conducting additional research on other Hospitals.

A second methodological limitation relates the problem of the reliability of the reported data collected to measure patient satisfaction. Patients' statements may be affected by their worries with the staff, for fear or ignorance.

A third limitation is the relatively small number of selected hospitals. A more comprehensive study covering all the Tunisian territory can be considered and thus may reach more reliable results.

In this context we will consider a theoretical and empirical study that takes into account all these limitations and would, among other things, focus on the importance of the variable "respect for privacy" to patient satisfaction in Tunisian hospitals.

\section{References:}

1. $\quad$ Allen H.M., Rogers W.H. (1996) : «Consumer Surveys of Health Plan Performance : a Comparison of Content and Approach and a look to the Future", J Qual Improv, 22, pp. 775-794.

2. Bielen F. (2001) : «Orientation-patient et qualité perçue du service : analyse marketing appliquée à la gestion hospitalière», Thèse de Doctorat, Université Catholique de Louvain, Faculté des Sciences Économiques, Sociales et Politiques, $457 \mathrm{p}$.

3. Bielen F. et D'Hoore W. (2002) : «Qualité perçue du service et satisfaction du patient à l'égard de l'hôpital», Actes de la conférence CALASS (Congrès de l'Association Latine pour l'Analyse des Système de Santé)

4. Brand, R. R., Cronin, J.J, et al, (1997), «Marketing of older Patients: Perception of Service Quality», Health Marketing Quaterly, 15, 2, 1-31.

5. Brown, T.J., and Kirmani, A., (1999), «The influence of Preen counter Affect on Satisfaction with an Anxiety-Provoking service Encounter», Journal of Service Research, 1, 4, pp. 333-346.

6. Bruster S., Jarman B., Bosanquet N., Weston D., Erens R., Delbanco T., (1994): «National Survey of Hospital Patients», Br Med J , 309, pp. 1542-1546.

7. Dubé, M., Bélanger, C., et al (1996), «The role of emotion in Health care Satisfaction», J ournal of Health care Marketing, 144-145.

8. Eiglier,P., et Langlard ,E., (1987), «Servuction - le Marketing des services», édition Mc Graw-Hill, p.90.

9. Gasquet I. (1999) : «Satisfaction des patients et performance hospitalière», La Presse Médicale, 28, pp. 16.

10. Hall JA, Milburn MA, Esptein AM (1993): «A Causal Model of Health Status and Satisfaction with Medial Care», Med Care, 31, pp. 84-94.

11. Materko M, Rubin H.R (1990): «Patient Judgements of Hospital Quality: a Taxonomy », Méd care, 28 (9 Suppl), pp. 10S-14S.

12. Kolb, S. J., Race, K.E.H., et al, (2000), «Psychometric Evaluation of an Inpatient Psychiatric care consumer satisfaction Survey », The J ournal of Behavioral Health Services and Research, 1, 27, February, pp. 75-86.

13. Parasuraman, A., Zeithmal, V., et Berry, L., (1985) «A coneptual model of service quality and its implication for future research», journal of Marketing, vol.49, pp. 41-50. 
14. Pascoe, G.C., (1983), «Patient Satisfaction in Primary Health care: A literature Review and analysis », Eval progr Plan 6, pp. 185-210.

15. Pourin.C., Barberger Gateau, P., Michel, P., et Salamon, R., (1999), «la mesure de la satisfaction des patients hospitaisés - 1 ére partie: Aspect conceptuel et Revue des travaux », J ournal d'économie médicale, vol.17, N²- 3, 103, pp. 101-115.

16. Prévost A. et Fafard A. (1996) : «La mesure de la satisfaction des usagers dans le domaine de la santé et des services sociaux : outil de régulation du système», Régie régionale de la santé et des services sociaux Chaudière-Appalaches, Québec, 156 p.

17. Rubin HR, (1990): «Can Patients Evaluate the Quality of Hospital Care?», Med Care Rev, 47, pp. 267-326.

18. Sabadie, W., (2000), le droit des usagers à la justice et à la qualité du service public, XVéme journées nationales des IAE.

19. Salomon L., Gasquet I., Mesbah M. et Ravaud Ph. (1999) : «Construction of a Scale Measuring Impatients' Opinion on Quality of Care», International J ournal in Health Care, Vol, 11, $\mathrm{N}^{\circ} 6$, pp 507-516.

20. Singh. J., (1990), «A Multiface Typology of patient satisfaction with a hospital stay», journal of Health care Marketing, 10, 4, 8-21.

21. Staines, A., (1995), «la gestion des attentes de la population à l'égard du système de santé : actions possibles dela part des pouvoirs publics», Santé publique, 3, pp. 339-349.

22. Suuroja, M., (2003), «Service quality- Main conceptualization and critique », working paper, university of Tartu. Marketing des services», édition Mc Graw-Hill, p. 90.

23. Ware, J. E, and Synder, M., (1975), «Dimensions of patient attitudes regarding Doctors and Medical care services», Medical care, 13, August, pp. 669-682.

24. Ware J.E, Snyder MK, Russel-Wright W, Davies AR (1983): «Defining and Measuring Patient Satisfaction with Medical Care», Eval Progr Plan, 6, pp. 247-263. 